\title{
Detection of hereditary motor sensory neuropathy type I in childhood
}

\author{
T E Feasby, A F Hahn, C F Bolton, W F Brown, W J Koopman
}

\begin{abstract}
Clinical signs and slowed motor nerve conduction velocities were found in 17 of 36 children under 10 years of age who had one parent with hereditary motor sensory neuropathy type I (HMSN I). Four children had slowed conduction velocities at one year or less. Clinical signs were subtle and included pes planus, distal foot wasting, weakness of ankle eversion and dorsiflexion and areflexia. HMSN I can be detected reliably in children, even before one year of age.
\end{abstract}

(F Neurol Neurosurg Psychiatry 1992;55:895-897)

University of Western of Clinical

Neurological Sciences, London, Ontario, Canada

T E Feasby

A F Hahn

C F Bolton

W F Brown

W J Koopman

Correspondence and reprint requests to: Dr T E Feasby,

Department of Clinical

Nepartment of Clinical
Neurosciences, University of Calgary, Foothills Hospital, Calgary, Foothills Hos Calgary, Alberta T2N 2T9, Canada

Received 24 September 1991

and in revised form

15 January 1992 .

Accepted 23 January 1992 Ontario, Department

Transmission of hereditary motor sensory neuropathy type I (HMSN I) is usually dominant ${ }^{1}$ and the condition is often expressed in childhood. ${ }^{2}$ Affected adults frequently wish to know whether their children are, or will be, affected. This information may be readily obtained by genetic methods soon but currently, clinical and electrophysiological methods must suffice. The size of HMSN I families available for linkage analysis studies is sometimes limited by uncertainty of diagnosis in children. The ability to detect HMSN I reliably in children would increase the number of individuals for study.

The objective of this project was to determine the reliability of detection of HMSN I in children at risk using readily available and

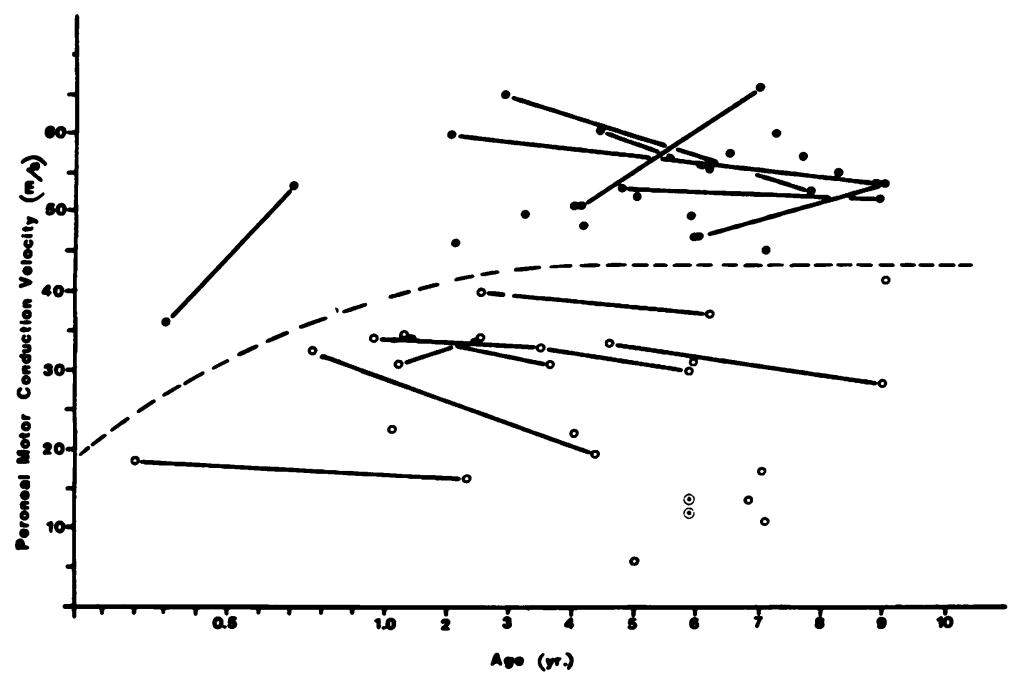

Figure Peroneal nerve motor conduction velocities in all subjects. (- - ) Lower limit of normal, two standard deviations below the mean;(O) clinically unaffected children; (O)

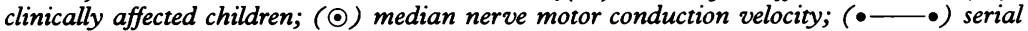
recordings in individual subjects. inexpensive clinical and electrophysiological methods.

\section{Patients and methods}

Thirteen families with well documented HMSN I, each involving at least two generations and with an inheritance pattern of dominant transmission, were studied. All families had typical clinical features and slowed nerve conduction velocities. ${ }^{24-6}$ In each family, the propositus had a median nerve motor conduction velocity of less than $38 \mathrm{~m} / \mathrm{s}^{2}$ Patients with diabetes were excluded. Nerve biopsies were obtained from members of four families and all showed the histological features of demyelination, remyelination and onion bulb formation typical of HMSN I. ${ }^{7}$ Genetic linkage studies done previously in three of these families showed linkage to a marker on chromosome $17^{8}$ allowing them to be classified as HMSN Ia. ${ }^{9}$

Each available child under 10 years of age who had an affected parent was examined. The diagnosis of HMSN I had previously been verified in the parent of every child. Each child was examined neurologically and the findings were recorded before electrophysiological testing.

Electrophysiological studies were carried out on each patient, using standard techniques, after the clinical assessment. Motor conduction in the peroneal nerve was studied by stimulation of the nerve at the knee and the ankle while recording from the extensor digitorum brevis muscle using surface electrodes. The velocity was considered to be abnormal when it was more than two standard deviations below the mean normal velocity for age (fig). The normal values were taken from our own age-matched laboratory controls and were similar to those of Gamstorp. ${ }^{10}$ In two patients, only median motor conduction studies were done. Sensory potentials were recorded from the sural nerve or the superficial peroneal nerve with surface electrodes.

Serial studies were done in the younger patients when possible. One child of nine months who had a borderline peroneal nerve conduction velocity $(40 \mathrm{~m} / \mathrm{s})$ was excluded from analysis because she could be assessed only once.

\section{Results}

Twenty-three children were studied on one occasion and 13 were studied more than once. Seventeen of the 36 subjects $(47 \%)$ had 
Table 1 Clinical and electrophysiological data

\begin{tabular}{|c|c|c|c|c|c|c|c|}
\hline Family & Child & Sex & $\begin{array}{l}\text { Age } \\
\text { (years) }\end{array}$ & $\begin{array}{l}\text { Peroneal motor } \\
\mathrm{CV}(\mathrm{m} / \mathrm{s})\end{array}$ & $\begin{array}{l}\text { Sural or superficial } \\
\text { peroneal sensory nerve } \\
\text { CVlamplitude } \\
(\mathrm{m} / \mathrm{s} / \mu \mathrm{V})\end{array}$ & Clinical abnormalities & $\begin{array}{l}\text { Affected }(Y) \text { or not } \\
\text { affected }(N)\end{array}$ \\
\hline $\mathbf{A}$ & $\begin{array}{l}1 \\
2\end{array}$ & $\begin{array}{l}\mathbf{F} \\
\mathbf{M}\end{array}$ & $\begin{array}{l}6 \cdot 9 \\
4 \cdot 0\end{array}$ & $\begin{array}{l}14 \\
53\end{array}$ & $\begin{array}{c}0 / 0 \\
60 / 20\end{array}$ & Pes planus, areflexia & $\mathbf{Y}$ \\
\hline \multirow{8}{*}{$\stackrel{\text { B }}{\mathbf{C}}$} & 3 & M & 9 & 41 & $36 / 7$ & Pes planus, weak TA, thin EDB & $\mathrm{Y}$ \\
\hline & 4 & $\mathbf{M}$ & 7 & 11 & $0 / 0$ & $\begin{array}{l}\text { Pes cavus, thin EDB, weak } \\
\text { hands and TA, } \downarrow \text { pin and } \\
\text { vibration sense in feet, } \\
\text { areflexia }\end{array}$ & $\mathbf{Y}$ \\
\hline & 5 & $\begin{array}{l}M \\
9\end{array}$ & $\begin{array}{l}6 \\
54\end{array}$ & 47 & $45 /-$ & - & $\mathbf{N}$ \\
\hline & 6 & $\mathbf{F}$ & $\begin{array}{l}4 \\
7\end{array}$ & $\begin{array}{l}53 \\
66\end{array}$ & $50 /-$ & - & $\mathbf{N}$ \\
\hline & 7 & $\mathbf{M}$ & $\begin{array}{l}4 \cdot 8 \\
8 \cdot 9\end{array}$ & $\begin{array}{l}54 \\
52\end{array}$ & $\begin{array}{l}49 / 20 \\
-\end{array}$ & - & $\mathbf{N}$ \\
\hline & 8 & $\mathbf{M}$ & $5 \cdot 5$ & 13 & - & $\begin{array}{l}\text { Pes planus, thin EDB, weak TA, } \\
\text { areflexia }\end{array}$ & $\mathbf{Y}$ \\
\hline & 9 & $\mathbf{F}$ & $6 \cdot 5$ & 57 & - & - & $\mathbf{N}$ \\
\hline & 10 & $\mathbf{F}$ & $3 \cdot 2$ & 49 & - & - & $\mathbf{N}$ \\
\hline \multirow[t]{8}{*}{ D } & 11 & $\mathbf{M}$ & $\begin{array}{l}2 \cdot 5 \\
6 \cdot 2\end{array}$ & $\begin{array}{l}40 \\
37\end{array}$ & - & $\begin{array}{l}\text { Thin EDB, weak TA } \\
\text { Prominent SPN }\end{array}$ & $\mathbf{Y}$ \\
\hline & 12 & $\mathbf{M}$ & $\begin{array}{l}0 \cdot 8 \\
4 \cdot 3\end{array}$ & $\begin{array}{l}32 \\
20\end{array}$ & - & Pesplanus, thin EDB, weak TA & $\mathbf{Y}$ \\
\hline & 13 & $\mathbf{M}$ & $\begin{array}{l}2 \\
8 \cdot 9\end{array}$ & $\begin{array}{l}60 \\
54\end{array}$ & $52 / 18$ & - & $\mathbf{N}$ \\
\hline & 14 & $\mathbf{M}$ & 4.5 & $\begin{array}{l}34 \\
29\end{array}$ & $22 / 9$ & Pes planus, thin EDB, weak TA & $\mathbf{Y}$ \\
\hline & 15 & $\mathbf{M}$ & $\begin{array}{l}1 \cdot 0 \\
3.5 \\
5 \cdot 9\end{array}$ & $\begin{array}{l}34 \\
33 \\
30\end{array}$ & $\begin{array}{l}29 / 8 \\
0 / 0 \\
-\end{array}$ & $\begin{array}{l}\text { Normal } \\
\text { Pes planus, thin EDB, weak TA }\end{array}$ & $\mathbf{Y}$ \\
\hline & 16 & $\mathbf{M}$ & $\begin{array}{l}2 \cdot 9 \\
7.8\end{array}$ & 65 & $45 / 12$ & - & $\mathbf{N}$ \\
\hline & 17 & $\mathbf{F}$ & $1 \cdot 3$ & 34 & 二 & Thin EDB & $\mathbf{Y}$ \\
\hline & 18 & $\mathbf{F}$ & $\begin{array}{l}3 \cdot 0 \\
1 \cdot 2 \\
2 \cdot 5\end{array}$ & $\begin{array}{l}31 \\
32 \\
34\end{array}$ & $\bar{z}$ & $\begin{array}{l}\text { Areflexia } \\
\text { Pes planus, thin EDB }\end{array}$ & $\mathbf{Y}$ \\
\hline \multirow[t]{3}{*}{$\mathbf{E}$} & 19 & F & $4 \cdot 0$ & 22 & - & Weak TA, areflexic legs & $\mathbf{Y}$ \\
\hline & 20 & $\mathbf{M}$ & $8 \cdot 3$ & 56 & - & - & $\mathbf{N}$ \\
\hline & 21 & $\mathbf{M}$ & $7 \cdot 1$ & 48 & - & - & $\mathbf{N}$ \\
\hline \multirow[t]{5}{*}{$\mathbf{F}$} & 22 & $\mathbf{F}$ & $\begin{array}{l}0 \cdot 2 \\
2 \cdot 3\end{array}$ & $\begin{array}{l}19 \\
16\end{array}$ & $\overline{-}$ & $\begin{array}{l}\text { Absent AJ } \\
\text { Thin EDB, areflexia }\end{array}$ & $\mathbf{Y}$ \\
\hline & 23 & $\mathbf{F}$ & $7 \cdot 3$ & 61 & $50 / 10$ & - & $\mathbf{N}$ \\
\hline & 24 & $\mathbf{M}$ & $5 \cdot 9$ & 50 & $47 \cdot 7 / 10$ & - & $\mathbf{N}$ \\
\hline & 25 & $\mathbf{M}$ & $4 \cdot 2$ & 48 & - & - & $\mathbf{N}$ \\
\hline & 26 & $\mathbf{M}$ & $\begin{array}{l}0 \cdot 3 \\
0 \cdot 7\end{array}$ & $\begin{array}{l}36 \\
53\end{array}$ & & - & $\mathbf{N}$ \\
\hline \multirow[t]{3}{*}{ G } & 27 & $M$ & 6 & 47 & $42 \cdot 9 / 24$ & - & $\mathbf{N}$ \\
\hline & 28 & $\mathbf{M}$ & $7 \cdot 7$ & 57 & $43 \cdot 5 / 14$ & - & $\mathbf{N}$ \\
\hline & 29 & $\mathbf{F}$ & 5 & 52 & $52 \cdot 5 / 14$ & - & $\mathbf{N}$ \\
\hline $\mathbf{H}$ & 30 & $\mathbf{F}$ & $4 \cdot 5$ & 61 & - & $\begin{array}{l}\text { Thin EDB, decreased vibration } \\
\text { sense in fingers, reflexes } \\
\text { depressed }\end{array}$ & $\mathbf{N}$ \\
\hline & & & $6 \cdot 2$ & 56 & $48 \cdot 6 / 15 \cdot 8$ & & \\
\hline I & 31 & $\mathrm{M}$ & 1 & 23 & & $\begin{array}{l}\text { Left forefoot adducted, left } \\
\text { varus deformity }\end{array}$ & $\mathbf{Y}$ \\
\hline J & 32 & $\mathbf{M}$ & $5 \cdot 9$ & 12 (median) & $0 / 0$ & Pes planus, weak TA, areflexia & $\mathbf{Y}$ \\
\hline & 33 & $\mathbf{M}$ & & & - & Weak TA, areflexia & $\mathbf{Y}$ \\
\hline $\mathbf{K}$ & 34 & $\mathbf{F}$ & $5 \cdot 9$ & 12 (median) & $0 / 0$ & Pes cavus, areflexia, weak TA & $\mathbf{Y}$ \\
\hline $\begin{array}{l}\mathbf{L} \\
\mathbf{M}\end{array}$ & $\begin{array}{l}35 \\
36\end{array}$ & $\begin{array}{l}\mathbf{M} \\
\mathbf{F}\end{array}$ & $\begin{array}{l}6 \\
2 \cdot 1\end{array}$ & $\begin{array}{l}31 \\
46\end{array}$ & 二 & Absent AJ, weak TA & $\mathbf{Y}$ \\
\hline
\end{tabular}

$\mathrm{CV}=$ Conduction velocity; $\mathrm{TA}=$ tibialis anterior and peroneal muscles; $\mathrm{EDB}=$ extensor digitorum brevis muscle; SPN = superficial peroneal nerve; $\mathrm{AJ}=$ ankle jerks.

HMSN I based on clinical and electrophysiological criteria.

The clinical signs were often quite subtle. All but one of the affected children had clinical abnormalities when first seen (tables 1 and 2). The one patient (case 15) who was clinically normal when first seen at 1 year of age, had definite abnormalities when seen subsequently at 3.5 years of age. The most common foot deformity was pes planus which was present in 8 of 17 patients. Only two patients (ages 5.9 and 7) had pes cavus. Twelve had weakness of ankle dorsiflexion or eversion, and nine had

Table 2 Clinical findings in 17 children with HMSN I

\begin{tabular}{lr}
\hline Ples planus & 8 \\
Pes cavus & 2 \\
Thin extensor digitorum brevis muscle & 9 \\
Weak tibialis anterior or peronei & 12 \\
Areflexia-partial & 3 \\
-complete & 8 \\
Nerve hypertrophy & 1 \\
\hline
\end{tabular}

thin extensor digitorum brevis muscles. Seven children were areflexic and three had absent ankle jerks. Only one child (case 11 at age $6 \cdot 2$ ) had definite nerve hypertrophy. No child was disabled although several were quite clumsy.

Only one of 19 children with normal conduction studies had positive physical findings (case 30 ). When 6.2 years old, this girl had thin extensor digitorum brevis muscles, decreased vibration sensation in her fingers and areflexia. However, conduction studies were clearly normal.

Motor nerve conduction velocities were abnormally slow in the 17 affected children (table 1; Fig). In all but one of the affected patients, they were less than the $40 \mathrm{~m} / \mathrm{s}$. In that one patient (case 3 ), the peroneal maximum motor conduction velocity was $41 \mathrm{~m} / \mathrm{s}$ but the sural sensory conduction velocity was even slower at $36 \mathrm{~m} / \mathrm{s}$.

Sensory potentials were abnormal in all seven children with HMSN I in whom they 
were tested. They were absent in four children when they were first assessed at ages 5.9-7 years old and in one child (case 15) on the second examination when 3.5 years old. In that child, the superficial peroneal sensory nerve action potential was reduced in size and conduction velocity when he was first studied at 1 year of age. The other two children studied (cases 3 and 14) both had slow maximum sensory nerve conduction velocities.

Five children were studied at 1 year of age or younger. Four had reduced peroneal nerve conduction velocities. Three of these children were studied again when older (ages 2.3, 4.3, $5 \cdot 9)$ and the slow conduction velocities were confirmed in each case.

Seven affected children had serial conduction velocity studies. In six cases, the conduction velocity decreased $(3-12 \mathrm{~m} / \mathrm{s})$ and in one it increased $(2 \mathrm{~m} / \mathrm{s})$ over an average interval of $3 \cdot 2(1 \cdot 3-4 \cdot 5)$ years. This resulted in an average decline of $1.3 \mathrm{~m} / \mathrm{s}$ per year.

\section{Discussion}

HMSN I can be diagnosed reliably in children at risk under 10 years old. We found that 17 of 36 children of parents with HMSN I had slowed motor conduction velocities and clinical signs. These findings, in children of a parent with definite HMSN I, allowed a positive diagnosis. This positivity rate of $47 \%$ is not significantly different from the $50 \%$ positivity that could be expected with complete penetrance of this neuropathy of dominant inheritence. Previous estimates of the penetrance rates have varied from $73 \%^{4}$ to $100 \% .^{1112}$

HMSN I is well known to present in childhood $^{313}$ but patients often do not have clinical symptoms until later. ${ }^{17}$ Our data show that virtually all affected subjects can be detected in early childhood. This result is similar to that of Berciano et $a^{14}$ who found electrophysiological or clinical evidence, or both, of HMSN I in 16 of 31 children at risk who were less than 10 years old. Nicholson ${ }^{12}$ also found evidence of HMSN I in 16 of 35 patients less than 11 years old. We found that even at 1 year of age or less, the motor conduction velocity was significantly slowed. In three of our four children with slowed conduction velocities at this age, repeat studies at older ages confirmed the positive result. This differs from the suggestion of Nicholson ${ }^{12}$ that typically slowed conduction velocity in $\mathrm{HMSN}$ I may not be detected reliably until the age of 5.

Serial studies of conduction velocity were done in seven affected children. The velocities dropped in five of six for an average decline overall of $1.3 \mathrm{~m} / \mathrm{s}$ per year. Previous studies have shown either a slight increase in conduction velocity with age ${ }^{15}$ or an increase in patients less than 40 years and a decrease in those over $40 .^{16}$ Nicholson $^{12}$ found no significant difference in motor conduction velocity comparing groups of patients older or younger than 20 years. These minor changes in conduction velocity with age are probably of no significance.

We detected abnormal physical findings in all children who were found to have slow conduction velocities. These signs were often subtle and usually not accompanied by disability. In many cases, they would have been insufficient for reliable diagnosis without conduction studies. This does emphasise, however, the early clinical expression of this disorder at a rate higher than previously recognised. Berciano et al $^{14}$ found decreased reflexes in $78 \%$ of patients under 10 years old but other signs were infrequent. Pes planus was the most common foot abnormality in our series, although many of the affected parents had pes cavus. Mild wasting of the extensor digitorum brevis muscle, weakness of the peroneal or tibialis anterior muscles or reduced reflexes were the other common signs. Clinical evidence of nerve hypertrophy was uncommon.

We thank Christina White, Hussein Remtulla and David Lovgren for excellent assistance.

1 Thomas PK. Classification and electrodiagnosis of hereditary neuropathies. In: Brown WF, Bolton CF, eds. Clinical Electromyography. Boston, MA: Butterworths, 1987: 177-207.

2 Harding AE, Thomas PK. The clinical features of Hereditary Motor and Sensory Neuropathy Types I and II. Brain 1980;103:259-80.

3 Ouvrier RA, McLeod JG, Conchin TE. The hypertrophic forms of motor and sensory neuropathy. A study of hypertrophic Charcot-Marie-Tooth disease (HMSN type I) and Dejerine-Sottas disease (HMSN III) in childhood. Brain 1987;110:121-48.

4 Dyck PJ, Lambert EH. Lower motor and primary sensory neuron disease with peroneal muscular atrophy. I. Neurologic, genetic and electrophysiological findings in hereditary polyneuropathy. Arch Neurol 1968;18:603-18.

5 Dyck PJ, Lambert EH. Lower motor and primary sensory neuron disease with peroneal muscular atrophy. II. Neurologic, genetic and electrophysiological findings in various neuronal degenerations. Arch Neurol 1968; various new

6 Thomas PK, Calne DB. Motor nerve conduction velocity in peroneal muscular atrophy: evidence for genetic heterogeneity. I Neurol Neurosurg Psychiatry 1974;37:68-75.

7 Dyck PJ. Inherited neuronal degeneration and atrophy affecting peripheral motor, sensory and automonic neurons. In: Dyck PJ, Thomas PK, Lambert EH, Bunge R, eds. Peripheral Neuropathy. Philadelphia, PA: W.B. Saunders, 1984:1600-55.

8 McAlpine PJ, Feasby TE, Hahn AF, et al. Localization of a locus for Charcot-Marie-Tooth Neuropathy Type Ia (CMT1a) to Chromosome 17. Genomics 1990;7: 408-15.

9 Dyck PJ, Ott J, Moore SB, Swanson CJ, Lambert EH. Linkage evidence for genetic heterogeneity among kinships with Hereditary Motor and Sensory Neuropathy, ships with Hereditary Motor and Sensory
Type I. Mayo Clin Proc 1983;58:430-5.

10 Gamstorp I. Normal conduction velocity of ulnar, median and peroneal nerves in infancy, childhood and adolescence. Acta Paediatr Suppl 1963;146:68-76.

11 Combarros O, Calleja J, Figols J, Cabello A, Berciano J. Dominantly inherited motor and sensory neuropathy type . Genetic, clinical, electrophysiological and pathological features in four families. $\mathcal{F}$ Neurol Sci 1983;61:181-91.

12 Nicholson GA. Penetrance of the hereditary motor and sensory neuropathy Ia mutation: assessment by nerve conduction velocities. Neurology 1991;41:547-52.

13 Vanasse M, Dubowitz V. Dominantly inherited peroneal muscular atrophy (Hereditary Motor and Sensory Neuropathy Type I) in infancy and childhood. Muscle and ropathy Type I) in inf
Nerve $1981 ; 4: 26-30$.

14 Berciano J, Combarros O, Calleja J, Polo J, Leno C. The application of nerve conduction and clinical studies to application of nerve conduction and clinical studies to genetic counselling in Hereditary Motor Sensory

15 Bradley WG, Madrid R, Davis C. The peroneal muscular atrophy syndrome. Clinical, genetic, electrophysiological and nerve biopsy studies, Part 3 . Clinical, electrophysiological and pathological correlations. If Neurol Sci 1977;32:123-36.

16 Dyck PJ, Karnes JL, Lambert EH. Longitudinal study of neuropathic deficits and nerve conduction abnormalities in hereditary motor and sensory neuropathy type I. Neurology 1989;39:1302-8. 